\title{
The existence of positive solutions for $p$-Laplacian boundary value problems at resonance
}

\author{
Weihua Jiang*, Jiqing Qiu and Caixia Yang
}

\section{"Correspondence:}

weihuajiang@hebust.edu.cn

College of Sciences, Hebei

University of Science and

Technology, Shijiazhuang, Hebei 050018, P.R. China

\section{照 Springer}

\begin{abstract}
By using the Leggett-Williams norm-type theorem due to O'Regan and Zima and constructing suitable Banach spaces and operators, we investigate the existence of positive solutions for fractional $p$-Laplacian boundary value problems at resonance. An example is given to illustrate the main results.
\end{abstract}

MSC: $34 \mathrm{~B} 15$

Keywords: positive solutions; -Laplacian operator; boundary value problem; resonance; Fredholm operator

\section{Introduction}

Boundary value problems at resonance have attracted more and more attention. Many authors studied the existence of solutions for these problems by using Mawhin's continuous theorem [1] and its extension obtained by Ge and Ren [2]; see [3-23] and the references cited therein. By using Leggett-Williams norm-type theorems due to O'Regan and Zima [24], the existence of positive solutions for the boundary value problems at resonance with a linear derivative operator has been investigated (see [25-28]). To the best of our knowledge, there is no paper to show the existence of a positive solution for boundary value problems with a nonlinear derivative operator (for instance, $p$-Laplacian operator) at resonance by using Leggett-Williams norm-type theorems. Motivated by the excellent results mentioned above, we will discuss the existence of positive solutions for the $p$-Laplacian boundary value problem

$$
\left\{\begin{array}{l}
{ }^{C} D_{0^{+}}^{\beta}\left[\varphi_{p}\left({ }^{C} D_{0^{+}}^{\alpha} x\right)\right](t)=f\left(t,\left({ }^{C} D_{0^{+}}^{\alpha} x\right)(t)\right), \quad t \in(0,1), \\
\left({ }^{C} D_{0^{+}}^{\alpha} x\right)(0)=\left({ }^{C} D_{0^{+}}^{\alpha} x\right)(1), \quad x^{(i)}(0)=0, \quad i=0,1,2, \ldots, n-1,
\end{array}\right.
$$

where $n-1<\alpha \leq n, 0<\beta<1, \varphi_{p}(s)=|s|^{p-2} s, p>1,{ }^{C} D_{0^{+}}^{\beta}$ is the Caputo fractional derivative (see $[29,30])$.

\section{Preliminaries}

For convenience, we introduce some notations and a theorem. For more details see [24].

Assume that $X, Y$ are real Banach spaces. A linear mapping $L: \operatorname{dom} L \subset X \rightarrow Y$ is a Fredholm operator of index zero (i.e. $\operatorname{dim} \operatorname{Ker} L=\operatorname{codim} \operatorname{Im} L<+\infty$ and $\operatorname{Im} L$ is closed in

(c) 2016 Jiang et al. This article is distributed under the terms of the Creative Commons Attribution 4.0 International License (http://creativecommons.org/licenses/by/4.0/), which permits unrestricted use, distribution, and reproduction in any medium, provided you give appropriate credit to the original author(s) and the source, provide a link to the Creative Commons license, and indicate if changes were made. 
$Y$ ) and an operator $N: X \rightarrow Y$ is nonlinear. $P: X \rightarrow X$ and $Q: Y \rightarrow Y$ are projectors with $\operatorname{Im} P=\operatorname{Ker} L$ and $\operatorname{Ker} Q=\operatorname{Im} L . J: \operatorname{Im} Q \rightarrow \operatorname{Ker} L$ is a isomorphism since $\operatorname{dim} \operatorname{Im} Q=$ $\operatorname{dim} \operatorname{Ker} L$. Denote by $L_{P}$ the restriction of $L$ to $\operatorname{Ker} P \cap \operatorname{dom} L \rightarrow \operatorname{Im} L$ and its inverse by $K_{P}$. So, $x$ is a solution of $L x=N x$ if and only if it satisfies $x=(P+J Q N) x+K_{P}(I-Q) N x$.

Let $C \subset X$ be a cone, $\gamma: X \rightarrow C$ be a retraction, $\Psi:=P+J Q N+K_{P}(I-Q) N$ and $\Psi_{\gamma}:=$ $\Psi \circ \gamma$.

Theorem 2.1 [24] Let $\Omega_{1}, \Omega_{2}$ be open bounded subsets of $X$ with $\bar{\Omega}_{1} \subset \Omega_{2}$ and $C \cap\left(\bar{\Omega}_{2} \backslash\right.$ $\left.\Omega_{1}\right) \neq \emptyset$. Assume that $L: \operatorname{dom} L \subset X \rightarrow Y$ is a Fredholm operator of index zero and the following conditions are satisfied.

(C1) $Q N: X \rightarrow Y$ is continuous and bounded and $K_{P}(I-Q) N: X \rightarrow X$ is compact on every bounded subset of $X$;

(C2) $L x \neq \lambda N x$ for all $x \in C \cap \partial \Omega_{2} \cap \operatorname{dom} L$ and $\lambda \in(0,1)$;

(C3) $\gamma$ maps subsets of $\bar{\Omega}_{2}$ into bounded subsets of $C$;

(C4) $d_{B}\left(\left.[I-(P+J Q N) \gamma]\right|_{\operatorname{Ker} L}, \operatorname{Ker} L \cap \Omega_{2}, 0\right) \neq 0$, where $d_{B}$ stands for the Brouwer degree;

(C5) there exists $u_{0} \in C \backslash\{0\}$ such that $\|x\| \leq \sigma\left(u_{0}\right)\|\Psi x\|$ for $x \in C\left(u_{0}\right) \cap \partial \Omega_{1}$, where $C\left(u_{0}\right)=\left\{x \in C: \mu u_{0} \preceq x\right.$ for some $\left.\mu>0\right\}$ and $\sigma\left(u_{0}\right)$ is such that $\left\|x+u_{0}\right\| \geq \sigma\left(u_{0}\right)\|x\|$ for every $x \in C$

(C6) $(P+J Q N) \gamma\left(\partial \Omega_{2}\right) \subset C$;

(C7) $\Psi_{\gamma}\left(\bar{\Omega}_{2} \backslash \Omega_{1}\right) \subset C$.

Then the equation $L x=N x$ has at least one solution in the set $C \cap\left(\bar{\Omega}_{2} \backslash \Omega_{1}\right)$.

Now, we present some fundamental facts on the fractional calculus theory which can be found in $[29,30]$.

Definition 2.1 The Riemann-Liouville fractional integral of order $\alpha>0$ of a function $y$ : $(0, \infty) \rightarrow R$ is given by

$$
I_{0^{+}}^{\alpha} y(t)=\frac{1}{\Gamma(\alpha)} \int_{0}^{t}(t-s)^{\alpha-1} y(s) d s
$$

provided the right-hand side is pointwise defined on $(0, \infty)$.

Definition 2.2 The Caputo fractional derivative of order $\delta>0$ of a function $y:(0, \infty) \rightarrow$ $\mathbb{R}$ is given by

$$
{ }^{\mathrm{C}} D_{0^{+}}^{\delta} y(t)=\frac{1}{\Gamma(n-\delta)} \int_{0}^{t}(t-s)^{n-\delta-1} y^{(n)}(s) d s,
$$

provided that the right-hand side is pointwise defined on $(0, \infty)$, where $n=[\delta]+1$.

Lemma 2.1 $[29,30]$ Assume $f \in L[0,1], q>p \geq 0, q>1$, then

$$
{ }^{\mathrm{C}} D_{0^{+}}^{p} I_{0^{+}}^{q} f(t)=I_{0^{+}}^{q-p} f(t), \quad{ }^{\mathrm{C}} D_{0^{+}}^{p} I_{0^{+}}^{p} f(t)=f(t) .
$$

Lemma $2.2[29,30]$ Assume $p>0$, then

$$
I_{0^{+}}^{p}{ }^{C} D_{0^{+}}^{p} f(t)=f(t)+c_{0}+c_{1} t+\cdots+c_{n-1} t^{n-1},
$$

where $n$ is an integer and $n-1<p \leq n$. 
Since ${ }^{\mathrm{C}} D_{0^{+}}^{\beta}\left[\varphi_{p}\left({ }^{\mathrm{C}} D_{0^{+}}^{\alpha}\right)\right]$ is a nonlinear operator, we cannot solve the problem (1.1) by Theorem 2.1. Based on this, we prove the following lemma.

Lemma $2.3 u(t)$ is a solution of the following problem:

$$
\left\{\begin{array}{l}
\left({ }^{\mathrm{C}} D_{0^{+}}^{\beta} u\right)(t)=f\left(t, \varphi_{q}(u(t))\right), \quad t \in[0,1] \\
u(0)=u(1),
\end{array}\right.
$$

if and only if $x(t)$ is a solution of $(1.1)$, where $x(t)=I_{0^{+}}^{\alpha} \varphi_{q}(u(t)), \frac{1}{p}+\frac{1}{q}=1$.

Proof Assume that $u(t)$ is a solution of the problem (2.1) and $x(t)=I_{0^{+}}^{\alpha} \varphi_{q}(u(t))$. Then $u(t)=$ $\left[\varphi_{p}\left({ }^{\mathrm{C}} D_{0^{+}}^{\alpha} x\right)\right](t)$ and $x^{(i)}(0)=0, i=0,1,2, \ldots, n-1$. Replaces $u(t)$ with $\left[\varphi_{p}\left({ }^{\mathrm{C}} D_{0^{+}}^{\alpha} x\right)\right](t)$ in $(2.1)$, we can see that $x(t)$ is a solution of (1.1).

On the other hand, if $x(t)$ is a solution of $(1.1)$ and $u(t)=\left[\varphi_{p}\left({ }^{C} D_{0^{+}}^{\alpha} x\right)\right](t)$, substituting $u(t)$ for $\left[\varphi_{p}\left({ }^{C} D_{0^{+}}^{\alpha} x\right)\right](t)$ in (1.1), we can see that $u(t)$ satisfies $(2.1)$.

In this paper, we will always suppose that $f \in[0,1] \times \mathbb{R} \rightarrow \mathbb{R}$ is continuous, $p>1, \varphi_{p}(s)=$ $s \cdot|s|^{p-2}, \frac{1}{p}+\frac{1}{q}=1, \alpha>0,0<\beta<1$.

\section{Main result}

Let $X=Y=C[0,1]$ with the norm $\|u\|=\max _{t \in[0,1]}|u(t)|$. Take a cone

$$
C=\{u(t) \in X \mid u(t) \geq 0, t \in[0,1]\} .
$$

Define operator $L: \operatorname{dom} L \subset X \rightarrow Y$ and $N: X \rightarrow Y$ as follows:

$$
(L u)(t)=\left({ }^{\mathrm{C}} D_{0^{+}}^{\beta} u\right)(t), \quad(N u)(t)=f\left(t, \varphi_{q}(u(t))\right),
$$

where

$$
\operatorname{dom} L=\left\{u(t) \mid u(t),{ }^{\mathrm{C}} D_{0^{+}}^{\beta} u(t) \in X, u(0)=u(1)\right\}
$$

Then the problem (2.1) can be written by

$$
L u=N u, \quad u \in \operatorname{dom} L
$$

Lemma 3.1 $L$ is a Fredholm operator of index zero. $K_{P}$ is the inverse of $\left.L\right|_{\operatorname{dom} L \cap \operatorname{Ker} P \text {, where }}$ $K_{P}: \operatorname{Im} L \rightarrow \operatorname{dom} L \cap \operatorname{Ker} P$ is given by

$$
K_{P} y(t)=\frac{1}{\Gamma(\beta)}\left[\int_{0}^{t}(t-s)^{\beta-1} y(s) d s-\frac{1}{\beta} \int_{0}^{1}(1-s)^{\beta} y(s) d s\right] .
$$

Proof It is easy to see that

$$
\operatorname{Ker} L=\{c \mid c \in \mathbb{R}\}, \quad \operatorname{Im} L=\left\{y \in Y \mid \int_{0}^{1}(1-s)^{\beta-1} y(s) d s=0\right\},
$$

and $\operatorname{Im} L \subset Y$ is closed. 
Define $P: X \rightarrow X, Q: Y \rightarrow Y$ as

$$
P u=\int_{0}^{1} u(t) d t, \quad Q y=\beta \int_{0}^{1}(1-s)^{\beta-1} y(s) d s
$$

Obviously, $P: X \rightarrow X, Q: Y \rightarrow Y$ are projectors and $\operatorname{Im} P=\operatorname{Ker} L, X=\operatorname{Ker} P \oplus \operatorname{Ker} L$.

It is easy to see that $\operatorname{Im} L \subset \operatorname{Ker} Q$. Conversely, if $y(t) \in \operatorname{Ker} Q$, take $u(t)=\frac{1}{\Gamma(\beta)} \int_{0}^{t}(t-$ $s)^{\beta-1} y(s) d s$. Then $u(t) \in \operatorname{dom} L$ and $L u={ }^{C} D_{0^{+}}^{\beta} u(t)=y(t)$. These imply $\operatorname{Ker} Q \subset \operatorname{Im} L$. Therefore $\operatorname{Im} L=\operatorname{Ker} Q$. For $y \in Y, y=(y-Q y)+Q y \in \operatorname{Im} L+\operatorname{Im} Q$. If $y \in \operatorname{Im} L \cap \operatorname{Im} Q$, then $y=Q y$ and $y \in \operatorname{Im} L=\operatorname{Ker} Q$. This means that $y=0$, i.e. $Y=\operatorname{Im} L \oplus \operatorname{Im} Q$. So, $\operatorname{dim} \operatorname{Ker} L=$ $\operatorname{codim} \operatorname{Im} L=1<+\infty$. $L$ is a Fredholm operator of index zero.

For $y \in \operatorname{Im} L$, it is clear that $K_{P} y \in \operatorname{dom} L \cap \operatorname{Ker} P$ and $L K_{P} y=y$. On the other hand, if $u \in \operatorname{dom} L \cap \operatorname{Ker} P$, by Lemma 2.2, we get

$$
\begin{aligned}
K_{P} L u(t) & =\frac{1}{\Gamma(\beta)}\left[\int_{0}^{t}(t-s)^{\beta-1} L u(s) d s-\frac{1}{\beta} \int_{0}^{1}(1-s)^{\beta} L u(s) d s\right] \\
& =I_{0^{+}}^{\beta}{ }^{C} D_{0^{+}}^{\beta} u(t)-I_{0^{+}}^{\beta+1} \mathrm{C} D_{0^{+}}^{\beta} u(1) \\
& =u(t)+c-I_{0^{+}}^{\beta+1}{ }^{C} D_{0^{+}}^{\beta} u(1) .
\end{aligned}
$$

Thus, $\int_{0}^{1} K_{P} L u(t) d t=\int_{0}^{1} u(t) d t+c-I_{0^{+}}^{\beta+1} C_{0^{+}}^{\beta} u(1)$. It follows from $u \in \operatorname{Ker} P$ and $K_{P} L u \in$ $\operatorname{Ker} P$ that $c-I_{0^{+}}^{\beta+1}{ }^{C} D_{0^{+}}^{\beta} u(1)=0$. So, we have $K_{P} L u=u, u \in \operatorname{dom} L \cap \operatorname{Ker} P$.

Define $J: \operatorname{Im} Q \rightarrow \operatorname{Ker} L$ as $J(c)=c, c \in \mathbb{R}$.

Thus, $J Q N+K_{P}(I-Q) N: X \rightarrow X$ is given by

$$
\left[J Q N+K_{P}(I-Q) N\right] u(t)=\int_{0}^{1} G(t, s) f\left(s, \varphi_{q}(u(s))\right) d s,
$$

where

$$
G(t, s)= \begin{cases}\beta(1-s)^{\beta-1}\left(1-\frac{t^{\beta}}{\Gamma(\beta+1)}+\frac{1}{\Gamma(\beta+2)}\right)-\frac{(1-s)^{\beta}}{\Gamma(\beta+1)}+\frac{(t-s)^{\beta-1}}{\Gamma(\beta)}, & 0 \leq s<t \leq 1, \\ \beta(1-s)^{\beta-1}\left(1-\frac{t^{\beta}}{\Gamma(\beta+1)}+\frac{1}{\Gamma(\beta+2)}\right)-\frac{(1-s)^{\beta}}{\Gamma(\beta+1)}, & 0 \leq t \leq s<1 .\end{cases}
$$

Lemma 3.2 $Q N: X \rightarrow Y$ is continuous and bounded and $K_{P}(I-Q) N: \bar{\Omega} \rightarrow X$ is compact, where $\Omega \subset X$ is bounded.

Proof Assume that $\Omega \subset X$ is bounded. There exists a constant $M>0$, such that $|N u|=$ $\left|f\left(t, \varphi_{q}(u(t))\right)\right| \leq M, t \in[0,1], u \in \bar{\Omega}$. So, $|Q N u| \leq M, u \in \bar{\Omega}$, i.e. $Q N(\bar{\Omega})$ is bounded. Based on the definition of $Q$ and the continuity of $f$ we know that $Q N: X \rightarrow Y$ is continuous.

For $u \in \bar{\Omega}$, we have

$$
\begin{aligned}
& \left|K_{P}(I-Q) N u(t)\right| \\
& \quad=\left|\frac{1}{\Gamma(\beta)}\left[\int_{0}^{t}(t-s)^{\beta-1}(I-Q) N u(s) d s-\frac{1}{\beta} \int_{0}^{1}(1-s)^{\beta}(I-Q) N u(s) d s\right]\right| \\
& \quad \leq \frac{1}{\Gamma(\beta)} \int_{0}^{t}(t-s)^{\beta-1}|N u(s)| d s+\frac{1}{\Gamma(\beta)} \int_{0}^{t}(t-s)^{\beta-1}|Q N u(s)| d s
\end{aligned}
$$




$$
\begin{aligned}
& +\frac{1}{\beta \Gamma(\beta)} \int_{0}^{1}(1-s)^{\beta}|N u(s)| d s+\frac{1}{\beta \Gamma(\beta)} \int_{0}^{1}(1-s)^{\beta}|Q N u(s)| d s \\
\leq & \frac{4 M}{\Gamma(\beta+1)}<+\infty .
\end{aligned}
$$

Thus, $\mid K_{P}(I-Q) N(\bar{\Omega})$ is bounded.

For $u \in \bar{\Omega}, 0 \leq t_{1}<t_{2} \leq 1$, we get

$$
\begin{aligned}
& \left|K_{P}(I-Q) N u\left(t_{2}\right)-K_{P}(I-Q) N u\left(t_{1}\right)\right| \\
& \quad=\frac{1}{\Gamma(\beta)}\left|\int_{0}^{t_{2}}\left(t_{2}-s\right)^{\beta-1}(I-Q) N u(s) d s-\int_{0}^{t_{1}}\left(t_{1}-s\right)^{\beta-1}(I-Q) N u(s) d s\right| \\
& \quad=\frac{1}{\Gamma(\beta)}\left|\int_{0}^{t_{1}}\left[\left(t_{2}-s\right)^{\beta-1}-\left(t_{1}-s\right)^{\beta-1}\right](I-Q) N u(s) d s+\int_{t_{1}}^{t_{2}}\left(t_{2}-s\right)^{\beta-1}(I-Q) N u(s) d s\right| \\
& \quad \leq \frac{2 M}{\Gamma(\beta)}\left[\int_{0}^{t_{1}}\left[\left(t_{1}-s\right)^{\beta-1}-\left(t_{2}-s\right)^{\beta-1}\right] d s+\int_{t_{1}}^{t_{2}}\left(t_{2}-s\right)^{\beta-1} d s\right] \\
& \quad=\frac{2 M}{\Gamma(\beta+1)}\left[t_{1}^{\beta}-t_{2}^{\beta}+2\left(t_{2}-t_{1}\right)^{\beta}\right] .
\end{aligned}
$$

It follows from the uniform continuity of $t^{\beta}$ and $t$ on $[0,1]$ that $K_{P}(I-Q) N(\bar{\Omega})$ are equicontinuous on $[0,1]$. By the Arzela-Ascoli theorem, we see that $K_{P}(I-Q) N(\bar{\Omega})$ is compact.

In order to prove our main result, we need the following conditions.

$\left(\mathrm{H}_{1}\right)$ There exists a constant $R_{0}>0$, such that $f(t, u)<0, t \in[0,1], u>R_{0}$.

$\left(\mathrm{H}_{2}\right)$ There exist nonnegative functions $a(t), b(t)$ with $\max _{t \in[0,1]} \frac{1}{\Gamma(\beta)} \int_{0}^{t}(t-s)^{(\beta-1)} a(s) d s:=$ $A<+\infty, \max _{t \in[0,1]} \frac{1}{\Gamma(\beta)} \int_{0}^{t}(t-s)^{(\beta-1)} b(s) d s:=B<1 / 2$, such that

$$
|f(t, u)| \leq a(t)+b(t) \varphi_{p}(|u|) .
$$

$\left(\mathrm{H}_{3}\right) f(t, u) \geq-(1-t)^{1-\beta} \varphi_{p}(u) / \beta, t \in[0,1], u>0$.

$\left(\mathrm{H}_{4}\right)$ There exist $r>0, t_{0} \in[0,1]$, and $M_{0} \in(0,1)$ such that

$$
G\left(t_{0}, s\right) f(s, u) \geq \frac{1-M_{0}}{M_{0}} \varphi_{p}(u), \quad s \in[0,1), M_{0} r \leq u \leq r .
$$

$\left(\mathrm{H}_{5}\right) G(t, s) f(s, u) \geq-\varphi_{p}(u), s \in[0,1), t \in[0,1], u \geq 0$.

Lemma 3.3 If the conditions $\left(\mathrm{H}_{1}\right)$ and $\left(\mathrm{H}_{2}\right)$ hold, the set

$$
\Omega_{0}=\{u(t) \mid(L u)(t)=\lambda N u(t), u(t) \in C \cap \operatorname{dom} L, \lambda \in(0,1)\}
$$

is bounded.

Proof For $u(t) \in \Omega_{0}$, we get $Q N u(t)=0$ and $u(t)=\lambda I_{0^{+}}^{\beta} N u(t)+u(0)$. By $\left(\mathrm{H}_{1}\right)$ and $Q N u(t)=$ 0 , there exists $t_{0} \in[0,1]$ such that $\varphi_{q}\left(u\left(t_{0}\right)\right) \leq R_{0}$. This, together with $u(t)=\lambda I_{0^{+}}^{\beta} N u(t)+$ $u(0)$, means

$$
u(0) \leq u\left(t_{0}\right)+\left|\lambda I_{0^{+}}^{\beta} N u\left(t_{0}\right)\right| \leq \varphi_{p}\left(R_{0}\right)+\left|I_{0^{+}}^{\beta} N u\left(t_{0}\right)\right| .
$$


Thus, we have

$$
u(t) \leq u(0)+\left|\lambda I_{0^{+}}^{\beta} N u(t)\right| \leq \varphi_{p}\left(R_{0}\right)+\left|I_{0^{+}}^{\beta} N u\left(t_{0}\right)\right|+\left|I_{0^{+}}^{\beta} N u(t)\right| .
$$

It follows from $\left(\mathrm{H}_{2}\right)$ that

$$
\begin{aligned}
u(t) \leq & \varphi_{p}\left(R_{0}\right)+\frac{1}{\Gamma(\beta)} \int_{0}^{t_{0}}\left(t_{0}-s\right)^{\beta-1}\left|f\left(s, \varphi_{q}(u(s))\right)\right| d s \\
& +\frac{1}{\Gamma(\beta)} \int_{0}^{t}(t-s)^{\beta-1}\left|f\left(s, \varphi_{q}(u(s))\right)\right| d s \\
\leq & \varphi_{p}\left(R_{0}\right)+\frac{1}{\Gamma(\beta)} \int_{0}^{t_{0}}\left(t_{0}-s\right)^{\beta-1}[a(s)+b(s) u(s)] d s \\
& +\frac{1}{\Gamma(\beta)} \int_{0}^{t}(t-s)^{\beta-1}[a(s)+b(s) u(s)] d s \\
\leq & \varphi_{p}\left(R_{0}\right)+2(A+B\|u\|) .
\end{aligned}
$$

Therefore,

$$
\|u\| \leq \frac{\varphi_{p}\left(R_{0}\right)+2 A}{1-2 B}<+\infty .
$$

This means that $\Omega_{0}$ is bounded.

Theorem 3.1 Assume that the conditions $\left(\mathrm{H}_{1}\right)-\left(\mathrm{H}_{5}\right)$ hold. Then the boundary value problem (1.1) has at least one positive solution.

Proof Set

$$
\Omega_{1}=\left\{u \in X\left|M_{0}\|u\|<\right| u(t) \mid<r<R, t \in[0,1]\right\}, \quad \Omega_{2}=\{u \in X \mid\|u\|<R\}
$$

where $R>\max \left\{\varphi_{p}\left(R_{0}\right), \Gamma(\beta+1) A\right\}$ is large enough such that $\Omega_{2} \supset \Omega_{0}$. Clearly, $\Omega_{1}$ and $\Omega_{2}$ are open bounded sets of $X, \bar{\Omega}_{1} \subset \Omega_{2}$ and $C \cap\left(\bar{\Omega}_{2} \backslash \Omega_{1}\right) \neq \emptyset$.

In view of Lemmas 3.1,3.2, and 3.3, $L$ is a Fredholm operator of index zero and the conditions $(\mathrm{C} 1),(\mathrm{C} 2)$ of Theorem 2.1 are fulfilled.

Define $\gamma: X \rightarrow C$ as $(\gamma u)(t)=|u(t)|, u(t) \in X$. Then $\gamma: X \rightarrow C$ is a retraction and (C3) holds.

Let $u(t) \in \operatorname{Ker} L \cap \partial \Omega_{2}$, then $u(t) \equiv c= \pm R, t \in[0,1]$. Define

$$
H(c, \lambda)=c-\lambda|c|-\lambda \beta \int_{0}^{1}(1-s)^{\beta-1} f\left(s, \varphi_{q}(|c|)\right) d s .
$$

If $c=R, \lambda \in[0,1]$, by $\left(\mathrm{H}_{1}\right)$, we get

$$
H(R, \lambda)=R-\lambda R-\lambda \beta \int_{0}^{1}(1-s)^{\beta-1} f\left(s, \varphi_{q}(R)\right) d s>0 .
$$

If $c=-R, \lambda \in[0,1]$, by $\left(\mathrm{H}_{3}\right)$, we obtain

$$
H(-R, \lambda)=-R-\lambda R-\lambda \beta \int_{0}^{1}(1-s)^{\beta-1} f\left(s, \varphi_{q}(R)\right) d s<-(1+\lambda) R+\lambda R=-R .
$$

So, we have $H(u, \lambda) \neq 0, u \in \operatorname{Ker} L \cap \partial \Omega_{2}, \lambda \in[0,1]$. 
Therefore,

$$
\begin{aligned}
& d_{B}\left(\left.[I-(P+J Q N) \gamma]\right|_{\operatorname{Ker} L}, \operatorname{Ker} L \cap \Omega_{2}, 0\right) \\
& \quad=d_{B}\left(\left.H(\cdot, 1)\right|_{\operatorname{Ker} L}, \operatorname{Ker} L \cap \Omega_{2}, 0\right)=d_{B}\left(\left.H(\cdot, 0)\right|_{\operatorname{Ker} L}, \operatorname{Ker} L \cap \Omega_{2}, 0\right) \\
& \quad=d_{B}\left(\left.I\right|_{\operatorname{Ker} L}, \operatorname{Ker} L \cap \Omega_{2}, 0\right)=1 \neq 0 .
\end{aligned}
$$

Thus, (C4) holds.

Set $u_{0}(t)=1, t \in[0,1]$, then $u_{0} \in C \backslash\{0\}, C\left(u_{0}\right)=\{u \in C \mid u(t)>0, t \in[0,1]\}$. Take $\sigma\left(u_{0}\right)=$ 1 and $u \in C\left(u_{0}\right) \cap \partial \Omega_{1}$. Then $M_{0} r \leq u(t) \leq r, t \in[0,1]$. By $\left(\mathrm{H}_{4}\right)$, we get

$$
\begin{aligned}
\Psi u\left(t_{0}\right) & =\int_{0}^{1} u(s) d s+\int_{0}^{1} G\left(t_{0}, s\right) f\left(s, \varphi_{q}(u(s))\right) d s \\
& \geq \int_{0}^{1} u(s) d s+\int_{0}^{1} \frac{1-M_{0}}{M_{0}} u(s) d s \\
& \geq M_{0} r+\left(1-M_{0}\right) r=r=\|u\| .
\end{aligned}
$$

Thus, $\|u\| \leq \sigma\left(u_{0}\right)\|\Psi u\|$, for $u \in C\left(u_{0}\right) \cap \partial \Omega_{1}$. So, (C5) holds.

For $u(t) \in \partial \Omega_{2}, t \in[0,1]$, by the condition $\left(\mathrm{H}_{3}\right)$, we have

$$
\begin{aligned}
(P+J Q N) \gamma(u) & =\int_{0}^{1}|u(s)| d s+\beta \int_{0}^{1}(1-s)^{\beta-1} f\left(s, \varphi_{q}(|u(s)|)\right) d s \\
& \geq \int_{0}^{1}|u(s)| d s-\int_{0}^{1}|u(s)| d s=0 .
\end{aligned}
$$

So, $(P+J Q N) \gamma\left(\partial \Omega_{2}\right) \subset C$. Hence, $($ C6) holds.

For $u(t) \in \bar{\Omega}_{2} \backslash \Omega_{1}, t \in[0,1]$, it follows from $\left(\mathrm{H}_{5}\right)$ that

$$
\left(\Psi_{\gamma} u\right)(t)=\int_{0}^{1}|u(s)| d s+\int_{0}^{1} G(t, s) f\left(s, \varphi_{q}(|u(s)|)\right) d s \geq \int_{0}^{1}|u(s)| d s-\int_{0}^{1}|u(s)| d s=0 .
$$

So, (C7) is satisfied.

By Theorem 2.1, we confirm that the equation $L u=N u$ has a positive solution $u$. Based on Lemma 2.3, the problem (1.1) has at least one positive solution.

\section{Examples}

To illustrate our main result, we present an example.

Let us consider the following boundary value problem:

$$
\left\{\begin{array}{l}
{ }^{\mathrm{C}} D_{0^{+}}^{\frac{3}{4}}\left[\varphi_{\frac{5}{4}}\left({ }^{\mathrm{C}} D_{0^{+}}^{\frac{1}{2}} x\right)\right](t)=\frac{1}{4}(1-t)^{\frac{1}{4}}-\frac{1}{20}(1-t)^{\frac{1}{4}}\left|{ }^{\mathrm{C}} D_{0^{+}}^{\frac{1}{2}} x(t)\right|^{\frac{1}{4}}, \quad t \in(0,1), \\
x(0)=0, \quad\left({ }^{\mathrm{C}} D_{0^{+}}^{\frac{1}{2}} x\right)(0)=\left({ }^{\mathrm{C}} D_{0^{+}}^{\frac{1}{2}} x\right)(1) .
\end{array}\right.
$$

On the basis of Lemma 2.3, it is sufficient to examine the issue

$$
\left\{\begin{array}{l}
{ }^{C} D_{0^{+}}^{\frac{3}{4}} u(t)=\frac{1}{4}(1-t)^{\frac{1}{4}}-\frac{1}{20}(1-t)^{\frac{1}{4}}|u(t)|, \quad t \in[0,1] \\
u(0)=u(1)
\end{array}\right.
$$


Corresponding to the problem (2.1), we have $f(t, u)=\frac{1}{4}(1-t)^{\frac{1}{4}}-\frac{1}{20}(1-t)^{\frac{1}{4}}|u|^{\frac{1}{4}}, p=\frac{5}{4}$, $q=5, \alpha=\frac{1}{2}, \beta=\frac{3}{4}$. So,

$$
G(t, s)= \begin{cases}\frac{3}{4}(1-s)^{-\frac{1}{4}}\left(1-\frac{t^{\frac{3}{4}}}{\Gamma\left(\frac{7}{4}\right)}+\frac{1}{\Gamma\left(\frac{11}{4}\right)}\right)-\frac{(1-s)^{\frac{3}{4}}}{\Gamma\left(\frac{7}{4}\right)}+\frac{(t-s)^{-\frac{1}{4}}}{\Gamma\left(\frac{3}{4}\right)}, & 0 \leq s<t \leq 1, \\ \frac{3}{4}(1-s)^{-\frac{1}{4}}\left(1-\frac{t^{\frac{3}{4}}}{\Gamma\left(\frac{7}{4}\right)}+\frac{1}{\Gamma\left(\frac{11}{4}\right)}\right)-\frac{(1-s)^{\frac{3}{4}}}{\Gamma\left(\frac{7}{4}\right)}, & 0 \leq t \leq s<1 .\end{cases}
$$

Take $R_{0}=625, a(t)=1, b(t)=\frac{1}{4}, r=0.006, t_{0}=0$, and $M_{0}=0.95$.

Clearly, $\left(\mathrm{H}_{1}\right)$ holds. By simple calculations, we can see that

$$
\begin{aligned}
& |f(t, u)| \leq a(t)+b(t) \varphi_{p}(|u|), \\
& A=\max _{t \in[0,1]} \frac{1}{\Gamma\left(\frac{3}{4}\right)} \int_{0}^{t}(t-s)^{-\frac{1}{4}} d s=\frac{4}{3.6762}<+\infty, \\
& B=\max _{t \in[0,1]} \frac{1}{\Gamma\left(\frac{3}{4}\right)} \int_{0}^{t}(t-s)^{-\frac{1}{4}} \cdot \frac{1}{4} d s=\frac{1}{3.6762}<\frac{1}{2}, \\
& f(t, u) \geq-\frac{4}{3}(1-t)^{\frac{1}{4}} u^{\frac{1}{4}}, \quad u>0, \\
& G\left(t_{0}, s\right) f(s, u) \geq \frac{0.12828103}{4}-\frac{1.21630192}{20} u^{\frac{1}{4}} \\
& \quad \geq \frac{0.05}{0.95} u^{\frac{1}{4}}, \quad 0.0057 \leq u \leq 0.006, s \in[0,1), \\
& G(t, s) f(s, u) \geq-u^{\frac{1}{4}}, \quad u \geq 0, s \in[0,1), t \in[0,1] .
\end{aligned}
$$

So, the conditions $\left(\mathrm{H}_{1}\right)-\left(\mathrm{H}_{5}\right)$ hold. By Theorem 3.1, we can conclude that the problem (4.1) has at least one positive solution.

\section{Competing interests}

The authors declare that they have no competing interests.

\section{Authors' contributions}

All results belong to WJ, JQ, and CY. All authors read and approved the final manuscript.

\section{Acknowledgements}

This work is supported by the Natural Science Foundation of Hebei Province (A2017208101).

Received: 11 March 2016 Accepted: 13 September 2016 Published online: 27 September 2016

\section{References}

1. Mawhin, J: Topological Degree Methods in Nonlinear Boundary Value Problems. NSFCBMS Regional Conference Series in Mathematics. Am. Math. Soc., Providence (1979)

2. Ge, W, Ren, J: An extension of Mawhin's continuation theorem and its application to boundary value problems with a p-Laplacian. Nonlinear Anal. TMA 58, 477-488 (2004)

3. Ma, R: Existence results of a m-point boundary value problem at resonance. J. Math. Anal. Appl. 294, 147-157 (2004)

4. Xue, C, Ge, W: The existence of solutions for multi-point boundary value problem at resonance. Acta Math. Sin. 48, 281-290 (2005)

5. Du, Z, Lin, X, Ge, W: Some higher-order multi-point boundary value problems at resonance. J. Comput. Appl. Math. $177,55-65(2005)$

6. Feng, W, Webb, JRL: Solvability of $m$-point boundary value problems with nonlinear growth. J. Math. Anal. Appl. 212, 467-480 (1997)

7. Lian, H, Pang, H, Ge, W: Solvability for second-order three-point boundary value problem at resonance on a half-line. J. Math. Anal. Appl. 337, 1171-1181 (2008)

8. Zhang, X, Feng, M, Ge, W: Existence result of second-order differential equations with integral boundary conditions at resonance. J. Math. Anal. Appl. 353, 311-319 (2009)

9. Liu, B, Li, J, Liu, L: Existence and uniqueness for an $m$-point boundary value problem at resonance on infinite intervals. Comput. Math. Appl. 64, 1677-1690 (2012) 
10. Bai, C, Fang, J: Existence of positive solutions for three-point boundary value problems at resonance. J. Math. Anal. Appl. 291, 538-549 (2004)

11. Kosmatov, N: Multi-point boundary value problems on an unbounded domain at resonance. Nonlinear Anal. 68, 2158-2171 (2008)

12. Kosmatov, N: A boundary value problem of fractional order at resonance. Electron. J. Differ. Equ. 2010, 135 (2010)

13. Liu, B: Solvability of multi-point boundary value problem at resonance (II). Appl. Math. Comput. 136, 353-377 (2003)

14. Liu, B, Yu, J: Solvability of multi-point boundary value problem at resonance (III). Appl. Math. Comput. 129, 119-143 (2002)

15. Liu, Y, Ge, W: Solvability of nonlocal boundary value problems for ordinary differential equations of higher order. Nonlinear Anal. 57, 435-458 (2004)

16. Jiang, W: Solvability for a coupled system of fractional differential equations at resonance. Nonlinear Anal., Real World Appl. 13, 2285-2292 (2012)

17. Meng, F, Du, Z: Solvability of a second-order multi-point boundary value problem at resonance. Appl. Math. Comput. 208, 23-30 (2009)

18. Hu, L, Zhang, S, Shi, A: Existence result for nonlinear fractional differential equation with a $p$-Laplacian operator at resonance. J. Appl. Math. Comput. 48, 519-532 (2015)

19. Jiang, W: Solvability of fractional differential equations with a $p$-Laplacian at resonance. Appl. Math. Comput. 260, 48-56 (2015)

20. Lu, S: Homoclinic solutions for a class of second-order $p$-Laplacian differential systems with delay. Nonlinear Anal., Real World Appl. 12, 780-788 (2011)

21. Du, B: Homoclinic solutions for a kind of neutral differential systems. Nonlinear Anal., Real World Appl. 13, 168-175 (2012)

22. Feng, H, Lian, H, Gao, W: A symmetric solution of a multipoint boundary value problem with one-dimensional p-Laplacian at resonance. Nonlinear Anal. TMA 69, 3964-3972 (2008)

23. Lu, S: Periodic solutions to a second order $p$-Laplacian neutral functional differential system. Nonlinear Anal. TMA 69, 4215-4229 (2008)

24. O'Regan, D, Zima, M: Leggett-Williams norm-type theorems for coincidences. Arch. Math. 87, 233-244 (2006)

25. Infante, G, Zima, M: Positive solutions of multi-point boundary value problems at resonance. Nonlinear Anal. 69 , 2458-2465 (2008)

26. Chen, $Y$, Tang, $X$ : Positive solutions of fractional differential equations at resonance on the half-line. Bound. Value Probl. 2012, 64 (2012)

27. Zhang, $\mathrm{H}$, Sun, J: Positive solutions of third-order nonlocal boundary value problems at resonance. Bound. Value Probl. 2012, 102 (2012)

28. Zima, M, Drygas, P: Existence of positive solutions for a kind of periodic boundary value problem at resonance. Bound. Value Probl. 2013, 19 (2013)

29. Podlubny, I: Fractional Differential Equations. Academic Press, New York (1999)

30. Miller, KS, Ross, B: An Introduction to the Fractional Calculus and Fractional Differential Equations. Wiley, New York (1993)

\section{Submit your manuscript to a SpringerOpen ${ }^{\ominus}$ journal and benefit from:}

- Convenient online submission

Rigorous peer review

- Immediate publication on acceptance

- Open access: articles freely available online

- High visibility within the field

- Retaining the copyright to your article 